\title{
Poesia moçambicana e negritude: caminhos para uma discussão
}

SIMONE CAPUTO GOMES

Universidade de São Paulo

\begin{abstract}
RESUMO: BREVE ANÁLISE DOS IMPACTOS DOS MOVIMENTOS E ESTRATÉGIAS DE VALORIZAÇÃO DO NEGRO NA POESIA MOÇAMBICANA COMO VIA DE CONTESTAÇÃO DO APAGAMENTO IMPOSTO PELO SISTEMA COLONIAL ÀS IDENTIDADES CULTURAIS AFRICANAS. O PROCEDIMENTO UTILIZADO CONSISTIRÁ NA LEITURA DE TEXTOS DE NOÉMIA DE SOUSA, JOSÉ CRAVEIRINHA, VIRGILIO DE LEMOS E SÉRGIO VIEIRA, ENTRE OUTROS, BUSCANDO ACOMPANHAR A TRAJETÓRIA QUE SE ESTENDE DA RESISTÊNCIA CULTURAL À LUTA ARMADA EM MOÇAMBIQUE.
\end{abstract}

ABSTRACT: SHORT ANALYSIS OF IMPACTS OF MOVEMENTS AND STRATEGIES FOR INCREASE IN VALUE OF THE NEGRO IN MOZAMBICAN POETRY AS WAY TO CONTEST THE DELETION OF THE AFRICAN CULTURAL IDENTITIES IMPOSED BY THE COLONIAL SYSTEM. THE PROCEDURE CONSIST IN READING TEXTS OF NOÉMIA DE SOUSA, JOSÉ CRAVEIRINHA, VIRGILIO DE LEMOS AND SERGIO VIEIRA, AMONG OTHERS, SEEKING TO TRACK THE PROGRESS THAT EXTENDS FROM CULTURAL RESISTANCE TO STRUGGLE ARMED IN MOZAMBIQUE.

PALAVRAS-CHAVE: POESIA MOÇAMBICANA; IDENTIDADES CULTURAIS AFRICANAS; NEGRITUDE; NACIONALISMO CULTURAL; LUTA ARMADA.

KEYWORDS: MOZAMBICAN POETRY; AFRICAN CULTURAL IDENTITIES; NÉGRITUDE; CULTURAL NATIONALISM; ARMED STRUGGLE. 
ão será uma reivindicação de valores? A negritude não será uma revisão dos conceitos do Belo, a reabilitação de parâmetros culturais e cultuais, a crítica a tabus de rejeição, uma legítima defesa contra os padrões reacionários da superioridade pela tonalidade da pele, textura do cabelo, forma do nariz, lábios finos ou espessos? (...) Uma teoria da negritude através da literatura ou das artes plásticas, afinal, ofende a quem?

José Craveirinha

A vertente social, característica marcante das literaturas de língua portuguesa, encontrará em Moçambique, segundo Patrick Chabal (1994), respaldo nos movimentos de conscientização do negro ocorridos nos Estados Unidos e na Europa, levando a uma redescoberta do continente africano. Poetas como Orlando Mendes, Noémia de Sousa, José Craveirinha, Virgílio de Lemos, Sérgio Vieira, mesmo que não engajados diretamente a um desses movimentos, escolherão a via de autovalorização da cultura africana como contestatória da obliteração violenta imposta pelo sistema colonial. A experiência literária negritudinista é, nesse sentido, conforme postula Maria Nazareth Soares Fonseca,

um caminho que assegura o contato dos escritores com as idéias que propiciavam um conhecimento mais profundo da África e a contestação de uma visão preconceituosa sobre os africanos e sua cultura. Essa experiência, mesmo de forma indireta, está na base do nacionalismo africano ainda que tenha assumido em diferentes momentos características peculiares (FONSECA, 1997, p. 393-4).

Complementando a proposta da brasileira, Patrick Chabal ressalta que:

Embora nas colônias africanas portuguesas a negritude nunca tenha tomado a forma amplificada e exaltada que assumiu no império francês, houve um processo semelhante, mesmo que não tenha havido 'influência direta'. A negritude é, dessa forma, a mais explícita e manifesta fase de nacionalismo cultural que se pode encontrar na literatura africana moderna. (1994, p. 55)

Com base nessa argumentação, Orlando Mendes e Noémia de Sousa são considerados "pioneiros da moderna poesia moçambicana" (FERREIRA, 1977, p. 73). O primeiro mergulha sua poética na "seiva elementar/de África" 
(Ibidem); no caso de Noémia de Sousa, toda a sua produção ${ }^{1}$ alimenta-se das raízes africanas, é "África da cabeça aos pés":

Eu quero conhecer-te melhor, minha África profunda e imortal [...] Ó minha África misteriosa e natural, minha virgem violentada, minha Mãe! (Ibidem, p. 74-5)

Filha de mãe negra, Noémia transfere a maternidade biológica para a simbólica, elegendo a pele africana como o seu sinal: no poema "Negra", o corpo feminino, diverso, mas sintetizado numa única palavra, MÃE, acaba por representar o corpo do continente africano; e no poema "Sangue negro", estabelecida também a homologia entre "África" e "Mãe" pelo possessivo comum, "minha", o eu poemático assume o seu sangue negro-escravo e a sua ancestralidade originária:

E nada mais foi preciso, que o feitiço ímpar

dos teus tantãs de guerra chamando,

dundundundun-tã-tã-dun-dun-dun-tã-tã,

nada mais que a loucura elementar

dos teus batuques bárbaros, terrivelmente belos

- para que eu vibrasse,

- para que eu gritasse,

- para que eu sentisse, funda, no sangue, a tua voz, Mãe!

E, vencida reconhecesse os nossos elos...

E regressasse à minha origem milenar. (FERREIRA, 1985, p.92)

Em "Deixa passar o meu povo", poema antológico que dialoga com o spiritual Let my people go ${ }^{2}$, explicita-se a relação da poética de Noémia com os pressupostos do Harlem Renaissance:

1 Dezenas de poemas produzidos entre 1949 e 1952, dispersos pela imprensa moçambicana.

2 O tema do spiritual é o cativeiro de Moisés e do seu povo no Egito dos faraós. 
Noite morna de Moçambique

E sons longínquos de marimba chegam até mim

_certos e constantes _

Vindos nem eu sei donde.

Em minha casa de madeira e zinco,

Abro o rádio e deixo-me embalar...

Mas as vozes da América remexem-me a alma e os nervos.

E Robeson e Marian cantam para $\mathrm{mim}^{3}$

Spirituals negros de Harlem.

"Let my people go"

_ oh deixa passar o meu povo (...)

Nervosamente,

Sento-me à mesa e escrevo...

(Dentro de mim,

Deixa passar o meu povo (...)

$\mathrm{Na}$ minha mesa, vultos familiares se vêm debruçar (...)

Misérias, janelas gradeadas, adeuses de magaíças (...)

Pegando na minha mão e me obrigando a escrever

Com o fel que me vem da revolta. (...)

E enquanto me vierem de Harlem

vozes de lamentação

e os meus vultos familiares me visitarem

em longas noites de insônia,

não poderei deixar-me embalar pela música fútil

das valsas de Strauss.

Escreverei, escreverei,

com Robeson e Marian gritando comigo:

"let my people go"

OH DEIXA PASSAR O MEU POVO!

(FERREIRA, 1985, p. 94-5, grifos nossos)

3 Paul Robeson e Marian Anderson são figuras do mundo musical negro-americano, citadas também por José Craveirinha. 
A poeta coloca em diálogo "os sons que invadem a noite moçambicana vindos dos bairros pobres de madeira e zinco" e "as vozes negras que entoam, no Harlem distante, a conclamação à liberdade". Celebram-se "os cantos, as vozes negras americanas e de Moçambique, nelas repercutindo, por certo, os motivos sonoros de Guillén que cadenciam feições de uma identidade africana", esclarece-nos Maria Nazareth Fonseca (Afrodiccooes, site da Web).

A denúncia e o protesto anticolonial apresentados em voz de mulher e que tomam corpo feminino como símbolo de todas as formas de opressão e violência já são patentes na poesia de Noémia, em simultâneo com a valorização da cultura africana. A evocação da África-mãe, "ngoma pagã", com seus "batuques frenéticos", sua "feitiçaria", "humilhações" sofridas e "canções escravas", ecoa num grito de acusação "inchado de esperança" de mudança.

José Craveirinha qualifica Noémia como "o primeiro poeta verdadeiramente moçambicano no alto sentido da sua poesia e pelo nascimento" (Apud LARANJEIRA, 2000, p. 101). E acrescenta:

Noémia de Sousa foi quem soltou o primeiro canto da tragédia nocturna dos negros que trabalham na remoção dos dejectos da população dos subúrbios: os zampunganas. (...) só nós, os africanos das ruas de areia (...) só nós conhecemos a profundidade do soluço do zampungana:

Zampungana me chamam meus irmãos com os seus rostos negros amarrados de enjôo.

E até as mais baixas mulheres me recusam

e até os cães me ladram

até as crianças me têm medo

e até a vida me repudia! (...)

Minha vida

Ai excremento, excremento, excremento!

Para Craveirinha, Noémia é "o bardo dos Munhuanas, das Malangas e Xapamanines" e sua poesia, "mocharisse dja péla dambo" ou pássaro que, na hora do crepúsculo, solta o seu mais belo canto (Ibidem, p. 103). 
Cantora dos esquecidos, a poeta emprestará sua voz fraterna (“Nossa voz”) aos párias da África, exaltando a (es)cultura popular ("pau preto que um desconhecido irmão maconde talhou") e fundando o seu canto na sintonia cultural e política com movimentos do seu tempo, que envolviam a causa negra em outras partes do mundo: o Renascimento Negro americano, o Negrismo cubano de Nicolas Guillén ${ }^{4}$, o Regionalismo brasileiro de Jorge Amado, o Neo-Realismo português.

Publicações como Msaho (1952), O Brado Literário (1955), a revista Itinerário (1955), o Suplemento Paralelo 20 (1957-1961) e o Suplemento do Notícias, "Moçambique 58/panorama literário e artístico moçambicano" (16 números até 1959) impulsionarão, neste período, uma poética da "voz real de Moçambique" (FERREIRA, 1977, p. 79), que se nutre de posturas e valores africanos iluminados pelo substrato filosófico do pan-africanismo, do Renascimento Negro e da negritude.

Em plena luta armada surgem o jornal A voz de Moçambique (1961-1975) e o "Despertar" (Suplemento do Notícias). Em Lisboa, publica-se a antologia "Poetas moçambicanos" (1960), organizada por Luís Polanah, incluindo textos de poetas guerrilheiros da FRELIMO, como Sérgio Vieira; e em 1962, a antologia de mesmo nome organizada por Alfredo Margarido e também editada pela C.E.I., deixa entrever ligações com diversas correntes literárias como o Neo-realismo, a Negritude, o Surrealismo, entre outras (MENDONÇA, 1988, p.25).

Em 1967, já no âmbito dos órgãos culturais da FRELIMO, surge a coletânea Breve antologia de literatura moçambicana, organizada por Fernando Ganhão, cuja introdução fundamenta o conceito de literatura moçambicana como representação da realidade da luta de libertação nacional, atestando a passagem que se dará, nos anos sessenta, entre uma poética da valorização do "colonizado" - "o negro moçambicano que é vítima da opressão” (Apud MENDONÇA, 1988, p. IX-X) - e a poética dos guerrilheiros, que se consubstancia nas antologias publicadas pela FRELIMO de 1971 a 1977, sob o título de Poesia de Combate.

Para examinar com mais detalhe essa trajetória, voltamos à questão da apropriação dos pressupostos ou da poesia da negritude pelos moçambicanos. Virgílio de Lemos (um dos fundadores da revista $M$ saho) deixa clara a adesão à proposta de negritude em "Cantemos com os poetas do Haiti" (1960):

4 Dele é a epígrafe da antologia Poesia negra de expressão portuguesa, 1953, em que Noémia colaborou. 
Tu, Baby, e os poetas nossos irmãos

Que escrevem cânticos no Haiti,

Sabem da vida incerta e vazia

Dos negros das ilhas e Américas

Dos que sofrem em África e Oceania. (...)

Lembras-te dos segredos nas entrelinhas

Dos poemas verticais da Noémia de Sousa

Sempre em papel amarelo?

Cantemos com os poetas do Haiti

Uma canção amarga que se não perca

Cantemos em uníssono, porque lá ou aqui

Os segredos são iguais, fundos de angústia,

E os poemas verticais, também de desespero (FERREIRA, 1985, p. 155).

$\mathrm{Na}$ juventude, estudante de Antropologia e Literatura Inglesa na Universidade de Witts, Virgílio veio a incorporar o jazz negro do bas-fond sul-africano às suas vivências. Leitor de Fernando Pessoa, poeta então desconhecido, estreou-se em livro com um heterônimo, Duarte Galvão, um tipo múltiplo capaz de captar a negritude, de ser branco, chinês, crioulo, índio maia ou amazônico, indiano. Hoje, Virgílio de Lemos afirma que Duarte Galvão, que conheceu a poesia de Léopold Senghor e Aimée Cesaire, intuía que a negritude podia ser utilizada como arma de libertação do homem.

Seus poemas "Negro" (1952), em que tematiza a escravidão, "Paisagem" (1960, em que o protagonista do fio narrativo é o "negro gigante que se vai mirrando" nas minas do Rand), "Mãe negra" (1960), "Essa negra Tembê" (com ecos de "Essa nega Fulô", do brasileiro Jorge de Lima) e "Native Song n 1 " (1960) vão cantar o negro de todo o mundo e de todos os ofícios:

Aqui, José Mulato

Nos ritmos de sambas e brasis

Castro Alves dos lados do mato,

Ah Zixaxa e Mafalala

Ah, Xipamanine e Munhuana, 
Vai sonhando novos universos (...)

Aqui os sonhos cresceram

Porque os poemas verticais

Foram lidos, não se perderam.

Noémia escreveu poemas vigorosos

Que religiosamente se leram. (...)

Os negros que fumam ópio

e bebem canhos ou bagaços,

esses, Irmãos, não sonham (...);

mas os que fazem blocos de cimento,

os que vivem nas construções,

os que cantam no cais,

os que perfuram as minas do rand,

os que vendem peixe no bazar (...)

esses e só esses devem contar

para os grandes sonhos de luar,

em que as danças acordam anseios.

Anseios de sonhar com outro luar,

com Mary Anderson e Nova Orleans (...)

Irmãos dos versos que escrevi.

A medida do Universo, aqui

é a largueza dos sonhos de cada um. (Ibidem, p. 158-9).

Manuel Filipe de Moura Coutinho, também colaborador d'O Brado Literário (1955-7), resume o sentimento dos colaboradores daquele suplemento5:

Sou negro:

Negro como é negra a noite,

Negro como as profundezas

D’África. ${ }^{6}$

5 Noémia de Sousa, José Craveirinha, Marcelino dos Santos, Rui Nogar, Duarte Galvão-Virgílio de Lemos, entre outros.

6 A estrofe em destaque foi extraída do poema "Negro", de Langston Hughes. 
Irmão sempre colonial (...)

Negro Guillén, Hughes, Villa, Huerta

Negro intelectual

José, meu pobre engraxador (FERREIRA, 1985, p. 164).

Marcelino dos Santos (Kalungano), poeta e militante da revolução, exalta a mãe negra ("Mamã negra", "Sonho da mãe negra"), além de também evocar Langston Hughes, Césaire e Guillén no poema "Onde estou”:

Não

Não me procureis

onde não existo (...)

se eu estou aqui

bem vivo

na voz de Robeson e Hughes

Césaire e Guillén

Godido e Black Boy ${ }^{7}$ renascidos

nas entranhas da terra (ANDRADE, 1975, p. 159-160.)

Em seu trabalho poético (no qual não nos deteremos aqui) é possível observar a transmutação dos propósitos mais genéricos da conscientização negra (e/ou da negritude) em um mergulho na especificidade das transformações políticas moçambicanas:

Nas minhas veias

Corre o sol da terra austral (...)

Ó sol do meu país

Ó sol de Moçambique! (FERREIRA, 1985, p. 191-2)

7 Black Boy é o título de um dos romances de Richard Wright; Paul Robeson é músico, também citado por Noémia e Craveirinha. 
José Craveirinha, o "velho cravo", elabora o seu texto poético (ou "Manifesto") com "o sangue da [minha] mãe": o "grito negro" da Mãe-África percute na volúpia dos tantãs do xigubo. $\mathrm{E}$ o rosto do homem negro se destaca do fundo do auto-retrato, que tem como cenário a paisagem moçambicana:

meus belos e curtos cabelos crespos

e meus olhos negros (...)

e minha boca de lábios túmidos

cheios da bela virilidade ímpia de negro (...)

Oh! E meus dentes brancos de marfim

puros brilhando na minha negra reincarnada face altiva (CRAVEIRINHA, 1980, p. 33-4).

A poesia de Craveirinha opta por glorificar o homem africano, embora conceba a africanidade a partir do encontro de culturas, da mestiçagem, tendo por pressuposto, como expõe Appiah (1997, p. 241), uma constante reformulação e reflexão em torno dos interesses que movem as afirmações identitárias culturais e políticas. A partir dessa perspectiva, sua produção se apresenta como paradigmática, pois explora, com profundidade, as relações entre literatura e cultura africana, sem reduzi-las a propostas dicotômicas.

A opção pela África manifestou-se desde as primeiras criações de Craveirinha _ "Quando opto por Moçambique, eu estou a optar pela África" (entrevista a Chabal, 1994, p. 98) _, embora sua obra poética, avessa a rótulos e periodizações limitadores, tenha se relacionado de modo transformador e crítico com as principais correntes culturais e políticas de seu tempo (o neo-realismo, os movimentos negros americanos, a negritude, a luta pela libertação nacional), de modo a nunca admitir concessões quanto à qualidade literária dos textos.

Assim, José Craveirinha assumiu alguns dos pressupostos do movimento da negritude, como ao exaltar o orgulho de ser negro, com os valores e formas de expressão, sobretudo a oral, que a escolha acarretava.

Seu primeiro livro, Xigubo, obra de forte apelo identitário africano, abre-se com um poema dedicado a Claude Couffon, teórico da Negritude, ainda que explore também elementos da poesia neo-realista e da poesia revolucionária,

8 Poema dos anos quarenta. 
sem limitar-se, portanto, a qualquer pressuposto diretor. Em construção paralelística, ao som do tambor, a dança guerreira do tradicional xigubo, à volta da "fogueira amarela", "funde os negros" das tribos de ontem ("velhas tribos") e de hoje ("aqui outra vez"), seja este o tempo da escritura craveirínhica ou o tempo em ressonância percutiva de suas sucessivas gerações de leitores. Com suas "viris e ferozes catanas afiadas", ao som da onomatopeia ("Dum-dum!/tantã/ pés batem/tambores batem") que evoca o ritmo de "volúpia do xigubo, todos se unem para defender a mátria, a "mãe África" (CRAVEIRINHA, 1980, p. 9-10).

No poema "África", os mesmos "tantãs tribais" trazem à cena "navios negreiros", simbólicos da servidão imposta, mas azagaias rasgam o véu da noite colonial ("a noite africana") para mostrar ao mundo os "altivos falos de ouro erectos", "eros" do "grito" ou azagaias (catanas, no poema anterior) do verbo moçambicano transmutado no "rubi do mais belo canto xi-ronga" (Ibidem, p. 17).

Em ensaio fundamental para o estudo da relação da poesia de Craveirinha com a negritude, Rui Baltazar ressalta-lhe, poema a poema, um "traço dominante": é "um poeta negro no cantar e na forma, como parece ter resolvido o problema das suas origens" (s.d., p.5). Nos poemas "Mãe" e "Sangue de minha mãe" (Karingana ua karingana, 1982, p. 43 e 93) Craveirinha testemunha, pela via materna, uma natureza africana, num encontro com as raízes matriarcais. As "maternas palavras vivem e revivem no [...] sangue" do eu poemático, ao lado das sementes do pai, "português puro": o fruto da mestiçagem, ao tom "semiclaro", prefere o "seminegro", para "jamais renegar/ um glóbulo que seja do Zambeze” (Ibidem, p. 107).

A opção está feita. O corpo do eu lírico, identificado por inúmeros biografemas, confunde-se _ transformado em corpo coletivo ("nós, os negros, as mulatinhas/e as negras", Ibidem, p.132) _ com o do irmão explorado nas minas de carvão, do "cão" que apanha do patrão nos porões dos navios que deportam "barrigas negras” para S. Tomé, do negrinho "órfão de mãe ainda viva" exportada para as roças, da carga humana que "não tinha história" incendiada no barco Save, da "pura" mulata Margarida em "sua décima quinta blenorragia", do menino vadio e com fome assassinado no Chamanculo?.

9 Fragmentos extraídos de Xigubo. 
Assumida uma identidade ${ }^{10}$ negra, assim se define o eu poemático: "Eu sou carvão", "Eu (sou) chefe zulo/ Eu azagaia banto/Eu tambor/ Eu suruma/Eu negro suaili/ Eu Tchaca/ Eu Mahazul e Dingana/ Eu Zichacha/ Eu xiguilo no batuque" e, em resumo, "nas fronteiras de água do Rovuma ao incomáti/ Eu-cidadão dos espíritos das luas/carregadas de anátemas de Moçambique" (CRAVEIRINHA, 1980, p. 13 e 35).

José Craveirinha, ao adotar em Xigubo, narcisicamente11, com ímpeto e orgulho, um Eu múltiplo, representante da diversidade etnocultural moçambicana (os vários topônimos de Moçambique são uma constante em sua poética) e africana ("minha voz estentórea de homem Tanganhica/do Congo, Angola Moçambique e Senegal", p. 34), assume também os anátemas que se abatem sobre a África, especialmente a negra, vítima de feridas mais profundas:

céu onde existe o tal Deus que não sabe

línguas de África línguas de África línguas de África

e só sorriem anjos brancos de asas impossíveis de arminho

(...) ainda não há lugar par meninas puras da cor

das meninas filhas e netas de mães e avós pretas (1980, poema "Um céu sem anjos de África", p. 56-7).

Possante é o grito de indignação de Craveirinha, cuja poética vai, em progressão, erguendo-se como uma voz que passa do particular ao geral, do corpo individual ao corpo de Moçambique e da África _ sua paisagem física, humana ${ }^{12}$, suas línguas que irrompem no português legado para dizer:

as belas terras do (meu) áfrico País

e os belos animais (...) dos matos do (meu) País

e os belos rios e os belos lagos e os belos peixes

e as belas aves dos céus do (meu) País

e todos os nomes (eu amo) belos na língua ronga

macua, suaili, changana,

10 Entendida como identificação em curso, cf. SANTOS, 1995, p. 135.

11 Observe-se a reiteração do pronome eu.

12 Mulheres, crianças, jovens e velhos negros, que emergem das casas de caniço, das ruas de areia e da miséria, afastados da cidade branca. 
xítsua e bitonga

dos negros de Camunguine, Zavala, Meponda, Chissibuca

Zongoene, Ribáuè e Mossuril (Ibidem, p. 22).

O "Camões da Mafalala", como o denominou Mia Couto, recupera a oratura moçambicano-africana ("Quero ser tambor"), na sua maneira de conceber a poesia como profecia e prática narrativa: "Este jeito/ de contar as nossas coisas/ à maneira simples das profecias/_ Karingana ua karingana" é que "faz o poeta sentir-se gente" (1982, p. 13). Karingana na karingana é considerada uma obra de "interrogação ativa dos valores da identidade moçambicana" (JORGE, 2000, p. 201), poesia narrativa em que a expressão lírica busca a proximidade com a oralidade e, ao mesmo tempo, a ironia mordaz atua como poderosa estratégia de reflexão em torno da condição africana no mundo.

O texto "Quando eu penso na América" ou "Poema para Doreen Martin", nesse sentido, traduz a síntese do pensamento craveirínhico no que diz respeito ao impacto dos movimentos negros e demonstra como o poeta realiza a apropriação dos símbolos e heróis da negritude para representar, para além da questão rácica e da vitimização do negro, o seu direito ao sucesso e ao lugar de sujeito na História:

$\mathrm{Na}$ Mafalala quando eu penso na América

Um som de 'spiritual' geme no tal rio Mississipi

Um belo tiroteio desconsidera a vida de um transeunte (...)

Mas na história inconfundível

De Nova Orleães e Harlem

Estão lá Armstrong

Duke Ellington

Bessie Smith

Jessé Owens

Joe Louis

E Richard Wright.

E mais em toda a parte estão

Lá todos e também Ella Fitzgerald com suas vozes

Saltos

Murros e livros 
A lembrar os velhos e as crianças nas machambas de algodão E sem falta estão lá todos os negros do mundo nos 'juke-box' A tocar barato o que uma simples moeda quiser (...)

Mas lembrem-se que Jesse Owens foi aos Jogos Olímpicos E contra todas as expectativas ganhou 4 medalhas de ouro E sabem onde foi isso? Mesmo em Berlim. Joe Louis na desforra bateu Max Schmmeling por K.O. Armstrong dispara o trompete em cheio numa Coca-Cola Duke Ellington faz o piano colaborar em todos os problemas De jazz enquanto um prateado Cadillac obsceno atravessa A ponte de Brooklin como se fosse um insulto (...)

Mas as crianças que nascem nos becos de Xipamanine Ou nos irrespiráveis sótãos do Harlem (...)

Quando crescerem não se limitarão a cantar por cantar Não subirão ao ringue pelo simples fato de serem pugilistas

Nem ganharão os 100 metros só por uma questão de atletismo. (Apud LEITE, 1991, p. 142-144.)

Homenageando as figuras negras de destaque na música, no esporte e na literatura _ "Saltos/Murros e livros", Craveirinha relembra as vitórias de muitos em condições adversas para forjar a resistência de suas identidades africana e moçambicanas contra o poder destruidor: "o Daíco executa agora resvés no coração da pátria/de improviso a resistência da última posição/no corpo inteiro em contracanto" (CRAVEIRINHA, 1982, p. 113).

Do universalismo negro ao universalismo humano (toda a humanidade que sofre) move-se o canto do poeta-patriarca Craveirinha: da Mafalala, Moçambique, para o mundo (CHAVES, 1999):

Ah, Maria

põe as mãos e reza.

Pelos homens todos

E negros de toda a parte (CRAVEIRINHA, 1982, p. 164). 
José Craveirinha representa a mais alta expressão da moçambicanidade, porque sua vigorosa poesia explorou as potencialidades dos movimentos culturais e ideológicos do seu tempo, mas sempre extrapolando escolas e rótulos, operando uma interlocução com a boa poesia contemporânea sua, especialmente a de cariz identitário. Como enfatiza Fátima Mendonça, o

elemento de afirmação nacional que emerge, desde o inicio, da poesia de José Craveirinha, é pois gerado e produzido por um real definido e marcado, porventura apreendido pelo poeta numa fase em que a sua configuração não é perceptível a muitos: o poeta limitou-se a antecipar-se no tempo, captando e prevendo, assumindo-se finalmente como o "fabricante de vaticínios infalíveis" (...), o primeiro escritor a apresentar o espaço geográfico moçambicano em termos de nação. (...) Com ele surge pela primeira vez na poesia moçambicana escrita a afirmação nacionalista de comunidade e território [...] a opor-se à desintegração espacial que a política colonial preconizava (MENDONÇA, 2002. p. 54-55).

Essa poesia da "moçambicanidade" ("não sou luso-ultramarino/sou moçambicano"), que opta por percorrer uma africanidade de raiz ora míticotelúrica ora mítico-negritudinista, vai forjar e sedimentar os laços nacionais que levarão a uma poética guerrilheira, engajada ao ethos revolucionário da FRELIMO ${ }^{13}$ e à ideia de "Nação que ainda não existe" (Xigubo, 1980, p. 18) ou nação imaginada e profetizada em "Sia Vuma".

A par da produção de outros poetas que poderíamos associar a esse polo da afirmação nacionalista revolucionária, a poética de Sérgio Vieira representada pelo livro Também memória do povo ${ }^{14}$ (1983) parece-nos bem demonstrar como, a princípio herdeira de um discurso da negritude em poemas datados dos anos cinquenta e sessenta, migra para o âmbito da poesia de combate, colando-se ao discurso da luta armada. Observemos:

De teus seios negros

nasceram os rios do povo negro

13 Cuja criação Fátima Mendonça, 2002, p.56, chama de "forma superior deste processo de organização" vislumbrado por Craveirinha desde o poema "Chamamento", 1950.

14 Com desenhos de Malangatana e Chichorro. 
Eurídice

e o sol e o fogo

foram sol e fogo

nos teus olhos de África

Eurídice (...)

minha África-Eurídice (VIEIRA, 1983, p.9)

Sérgio Vieira, com seu "coração de negro" ("Poema”, 1960), canta, no início da década de sessenta, "os corpos negros/das crianças negras" "Quatro cantos para Ana Maria", 1961) e a "Terra Negra" (1961).

De 1965 a 1969, os laivos negritudinistas cederão lugar à contundência de longos poemas que tematizarão a guerra ("Tríptico para estado de guerra", p. 46-50, 1965) com riqueza de detalhes, assim como a morte do herói nacional Eduardo Mondlane. Em virtude desta, em "Pranto em forma de poema no luto do nosso povo" (1969, p. 51-76), coros de mulheres, velhos, crianças, poetas, camponeses, operários e mineiros, "todos órfãos", prantearão, "de rovuma ao maputo", "aquele que transportava o povo" (p. 53). Várias etnias moçambicanas (em voz coletiva) comporão o mosaico que se intitula "Povo" - makondes, macuas, shanganas, nyanjas - na "Pátria" concebida como "sinfonia das diferenças" (p. 61).

A postura anticolonialista e anti-imperialista explicita-se ("nós compreendemos que/o colonialismo português e o imperialismo/deviam morrer em moçambique", p.60) e "os filhos de moçambique" (poema "Nós") são o "braço armado do povo" com "bazookas" e "metralhadoras" para "libertar a pátria" (p. 68). O poema define-se como "grito" da vontade do povo (p. 68), "cântico de martírio" (p. 132), "canto de esperança" (p. 79), "cântico da liberdade" (p. 83). Morto Samora Machel, no quarto e último movimento do poema (Alvorada), a proposta é: "A LUTA CONTINUA", com a esperança de que, ao vermelho do sangue, substitua-se o "vermelho das buganvílias" ou da "flor de sangue" (p. 76 e 79).

Nos poemas datados dos anos setenta em diante (os mais recentes não são datados), o poeta começa cantando a memória dos navios negreiros ("No

15 "Poema para Eurídice Negra", datado de 1958. A partir daqui, os poemas de Vieira, 1983, serão indicados apenas pelo número da página. 
porto de escravos junto do mar nesse ano de mil novecentos e setenta", p. 41), a humilhação ("o grito/ de negro ignorante, ignorante, iignooraaaanteeee!", p. 92) e o sofrimento escravo (“de corrente nos pés", p. 87). E segue exaltando, em progressão cronológica, o momento em que "ninguém mais gritou/negro ignorante" (p. 99), o tempo em que prevalece "a vontade do Partido" (p. 20), em que desabrocham "as acácias vermelhas" a "implantar na Pátria" (p. 35) a "Nova Sociedade" (p. 35-36).

Ouve-se "o camarada ideólogo", "Marx", aprende-se "a ler e a escrever" (p. 101), cultua-se "as tradições da luta" (p. 37) e faz-se "a revolução" (p. 38). Em resumo: "aprende[-se] a história (...)/ descobr[e-se] a geografia da pátria/ nas lutas (...)/no mapa livre de Moçambique" (p. 102), na conquista do "verde dos campos", na "fusão do negro e branco do Povo unido, /erguendo a Paそ̌" (p. 133, grifos nossos). Que, muitas lutas e muito tempo depois, finalmente conquistada, ela perdure. Unem-se em coro a nossa voz e a de Sérgio Vieira à fala profética do Camões da Mafalala: "Sia Vuma"!

\section{Referência Bibliográfica}

ANDRADE, Mário de. Na noite grávida de punhais: antologia temática de poesia africana 1. Lisboa: Livraria Sá da Costa, 1975.

APPIAH, Kwame Anthony. Na casa de men pai. Rio de Janeiro: Contraponto, 1997.

BALTAZAR, Rui. Sobre a poesia de José Craveirinha. Cadernos de Consulta n. 7. Maputo: AEMO, s.d., republicado em Via Atlântica n. 5. São Paulo, 2002.

CHABAL, Patrick. Vozes Moçambicanas. Lisboa: Vega, 1994.

CHAVES, Rita. José Craveirinha, da Mafalala, de Moçambique, do Mundo. Revista Via Atlântica. USP-DLCV, n. 3, 1999. P. 140-168.

CRAVEIRINHA, José. Xigubo. Lisboa: edições 70, 1980. . Karingana ua Karingana. Lisboa: Edições 70, 1982. . Cela 1. Lisboa: Ediçções 70, 1980. . Maria. Lisboa: Caminho, 1998.

FERREIRA, Manuel. "Negritude, Negrismo, Indigenismo". In. O Discurso do Percurso Africano. Lisboa: Plátano, 1989. P. 57-83. . No reino de Caliban III. Lisboa: Plátano, 1985. . Literaturas africanas de expressão portuguesa. 1.ed. Lisboa. Instituto de

Cultura Portuguesa, 1977. V. 2. 
FONSECA, Maria Nazareth Soares. José Craveirinha: poesia com sons e gestos da oralidade. Scripta.: Literatura. Belo Horizonte: PUC Minas, 1997. V.6. n. 12. P. 388-400.

JORGE, Sílvio Renato. José Craveirinha e a busca da palavra moçambicana. In: África \&o Brasil: Letras em laços. Rio de Janeiro, Atlântica, 2000.

LEITE, Ana Mafalda. A poética de José Craveirinha. Lisboa: Vega, 1991. - A oficina narrativa da poesia na escrita de José Craveirinha. Revista Via Atlântica. USP-DLCV, n. 9, 2006. P. 225-240.

LARANJEIRA, Pires (org). A Negritude Africana de Lingua Portuguesa: textos de apoio (1947-1963). Braga: Angelus Novus, 2000.

MARGARIDO, Alfredo. Negritude e Humanismo. Lisboa, CEI, 1964.

MARTINHO, Fernando J. B. O negro norte-americano como modelo na busca de identidade para os poetas da África de Língua Portuguesa. In:-. Les Litteratures Africaines de Langua portugaise: a la recherche de l'identité individuelle et nationale. Actes du Colloque Internationao. Paris-Lisboa: Fondation Calouste Gulbenkian, 1985. P. 523-530.

MENDONÇA, Fátima e SAÚTE, Nelson. Antologia da nova poesia moçambicana. Maputo: AEMO, 1988.

. O conceito de nação em José Craveirinha, Rui Knopfli e Sérgio Vieira. In: Revista Via Atlântica, n. 5, 2002. P. 53-66.

SANTOS, Boaventura de Sousa. Pela mão de Alice: o social e o político na pós-modernidade. São Paulo: Cortez, 1995.

SECCO, Carmen Lucia Tindó Ribeiro. A apoteose da palavra e do canto: a dimensão 'neobarroca' da poética de José Craveirinha. In: Revista Via Atlântica, n. 5, 2002. P. 42-51.

SILVA, Manoel de Souza e. Do alheio ao próprio: a poesia em Moçambique. São PauloGoiânia: EDUSP-UFG-, 1996.

VIEIRA, Sérgio. Também memória do povo. Maputo: AEMO, 1983.

\section{WEBGRAFIA}

FONSECA, Maria Nazareth Soares. Afrodicções: matéria de poesia. Www.geocities.com/ail_br/afrodiccoes.html?200629.

LARANJEIRA, Pires. A negritude e a recepção lusófona, em segunda mão, de L'Etudiant Noir (Paris, 1935): de Mário Pinto de Andrade a Alfredo Margarido e Manuel Ferreira - balanço, homenagem e exortação. http:// www.uea-angola.org/artigo.cfm?ID=630. 